\title{
Transient Stability Improvement Using Neuro-Fuzzy Controller Design For STATCOM
}

\author{
${ }^{1}$ P.K.Dhal , ${ }^{2}$ Dr.C.Christober Asir Rajan \\ ${ }^{I}$ Research Scholar, Sathyabama University, Chennai - 600119 \\ ${ }^{2}$ Professor, Pondicherry Engineering College, Pondicherry - 605014
}

\begin{abstract}
This paper presents a transient stability improvement using neural-fuzzy controller design for STATCOM with static synchronous time critical error and better damping system oscillations after a short circuit fault. This article on a STATCOM Control for transient stability improvement has proposed a system to meet with the addition of Lyapunov stability criterion to the ability and conditions as well. The performance is analyzed using digital simulation with SMIB.
\end{abstract}

Keywords - Fuzzy Logic, Neural Network, lyapunov energy function, STATCOM, transient stability

\section{INTRODUCTION}

Development in electronics can power up, the interest using these elements as the high voltage network devices has increased. These elements not only in the steady state performance can be improved power systems are, but also its high speed compared to the system against disturbances. The generation of bulk power at remote locations necessitates the use of transmission line to connect generation sites to load centers. With long distance ac power transmission and load growth, active control of reactive power is indispensable to stabilize the power system and to maintain the supply voltage.

The static synchronous compensator (STATCOM) using voltage source inverters has been accepted as a competitive alternative to the conventional static VAr compensator (SVC) using thyristor-controlled reactors STATCOM functions as a synchronous voltage source. It can provide reactive power compensation without the dependence on the ac system voltage. By controlling the reactive power, a STATCOM can stabilize the power system, increase the maximum active power flow and regulate the line voltages. Faster response makes STATCOM suitable for continuous power flow control and power system stability improvement.

The interaction between the AC system voltage and the inverter-composed voltage provides the control of the STATCOM var output. When these two voltages are synchronized and have the same amplitude, the active and reactive power outputs are zero. However, if the amplitude of the STATCOM voltage is smaller than that of the system voltage, it produces a current lagging the voltage by $90^{\circ}$ and the compensator behaves as a variable capacitive load. This amplitude control is done through the leading the STATCOM voltage, it is possible to charge or discharge the dc capacitor; as a consequence, change the value of the dc voltage and the STATCOM's operational characteristics and the compensator behaves as an inductive load, which reactive value depends on the voltage amplitude. Making the STATCOM voltage higher than the AC system voltage the current will lead the voltage by $90^{\circ}$. In the past few decades, various STATCOM systems have been put into service. In this topology, multiple six-pulse inverters are magnetically coupled through a complex zig-zag transformer. An alternative approach is to use multilevel inverters [1-4], which can eliminate the bulky zig-zag transformer.

In [5], to eliminate unequal duty cycles, the required dc capacitance of each inverter unit is calculated according to the corresponding duty cycle. But in practical application modular design is very difficult. By using proposed method inverter units' fundamental output voltage are equalized. A special gating pattern is used for maintain the dc capacitor charge balance and equalize the current stress of the switching device. Among these various multilevel topologies, the cascaded multilevel inverter can implement a high number of levels with ease. The modular structure and the ease of redundant operation are also advantages.

In STATCOM to balance the dc-link voltages, additional auxiliary inverters were used to exchange the energy among various capacitors. But the disadvantage is high cost and complexity in hardware design. In conventional cascaded multilevel inverter use fundamental switching frequency [6] to generate step waveform at low harmonic distortion and keep the switching loss as low as possible. But the inverter units' duty cycles are different from each other. Due to unequal duty cycle the inverter units cannot equally share the exchanged power with the utility grid [7]. To overcome the limitations of semiconductor device, many new techniques are developed [8-10]. Recently alternate methods [11] of implementing these switching patterns have been developed without using real time solution of nonlinear harmonic elimination equation; an ANN is trained offline to output the switching angles for wanted output voltage. The ANN to be used for the generation of the 
optimal switching angles has a single input neuron fed by the modulation index, one hidden layer and $s$ outputs where each output represents a switching angle [11-13].

They are multiple switching elements in one leg of an inverter, series connected inverter and parallel connected inverters [14-15]. Fuzzy control and dynamic performance of STATCOM were analyzed and found that it was giving better performance than the without controller case. The time critical error was reduced and transient performance was improved [16]. Application of a fuzzy controller for transient stability enhancement of AC transmission system by STATCOM was analyzed and found that through the transient stability curve and concluded that the transient stability value was reduced in the considered method. But the rules framed are not made through the actual occurrence of a fault [17-18]. In this paper, the neuro-fuzzy controller (NFC) design for creating controller is very effective. This article on a STATCOM control for transient stability improvement has proposed a system to meet with the addition of Lyapunov stability criterion to the ability and conditions as well.

\subsection{Cascaded multilevel inverter}

\section{FUNDAMENTAL FREQUENCY MODULATION}

Fig. 1 shows the basic structure of cascaded multilevel inverter with separate dc source. For a three phase system, the output voltage of the three cascaded inverters can be connected either star or delta [4].

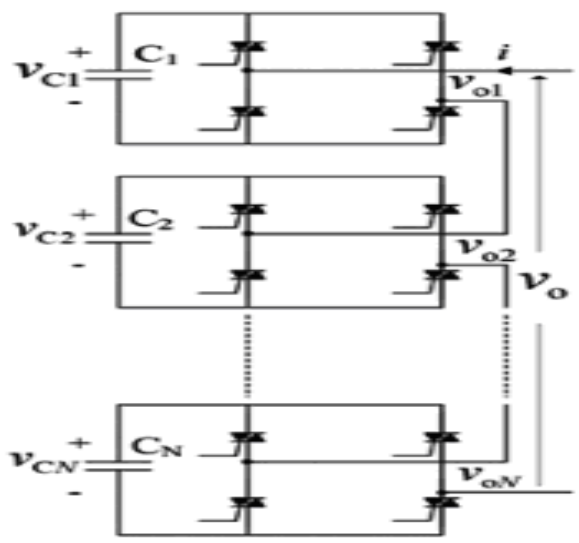

Fig 1: Basic Structure of Cascaded Multilevel Inverter

\subsection{Algorithm of the Multilevel Optimal Modulation}

\section{MULTILEVEL OPTIMAL MODULATION STRATEGY}

A 100Mvar STATCOM device is connected to the $230-\mathrm{kV}$ (L-L) grid network. Fig. 2 shows the single line diagram representing the STATCOM and the host sample grid network. The feeding network is represented by a Thevenin equivalent at (bus B1) where the voltage source is represented by a $\mathrm{kV}$ with 10,000 MVA short circuit power level with a followed by the transmission line connected to bus B2. The STATCOM device comprises the voltage source converter-cascade model connected to the host electric grid. 7-level is chosen here for STATCOM. It is connected to the network through the coupling transformer. The dc link voltage is provided by the capacitor $\mathrm{C}$ which is charged from the ac network. The decoupled current control system ensures full dynamic regulation of the bus voltage and the dc link voltage.

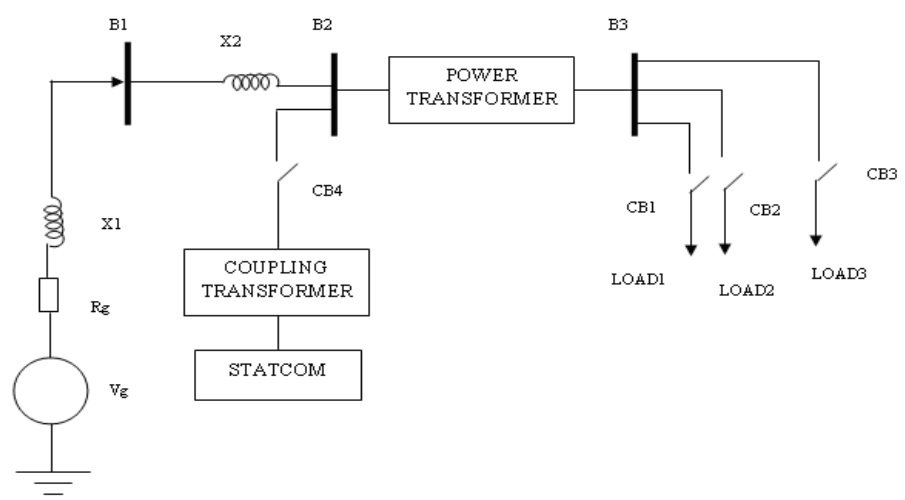

Fig 2: Single line Diagram representing the STATCOM

At the time of starting the source voltage is such that the STATCOM is inactive. It neither absorbs nor provides reactive power to the network. The following load sequence is tested and results are taken. At $\mathrm{t}=0.06 \mathrm{sec}$ STATCOM is connected to the system by switching circuit breaker CB4 . 
At $\mathrm{t}=0.1$ load 1 is connected by switching CB1.

At $\mathrm{t}=0.3$ load 2 is connected by switching CB2.

At $\mathrm{t}=0.5$ load 2 is connected by switching CB3.

STATCOM system is given in the Appendix.

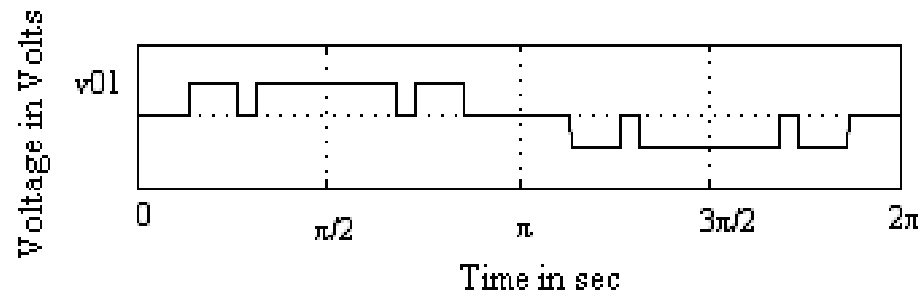

Fig 3: Waveforms of the output voltages of inverter units and their switching angles

Fig. 3 illustrates the typical output voltage waveforms when using the proposed optimal modulation strategy. The square wave is chopped three times per half cycle and the corresponding switching frequency of the IGCTs is $150 \mathrm{~Hz}$. The three switching angles of the inverter unit are depicted using. Since the waveform has quarter-wave and half wave symmetry, not even harmonics exist. And it is normalized with respect to the corresponding dc-link voltage.

\subsection{Gating-Pattern Swapping Among Various Devices}

Compared with the fundamental frequency technique, a disadvantage of $150 \mathrm{~Hz}$ modulation techniques is the unequal conduction time of the four switching devices in one inverter unit, as illustrated in Fig. 4
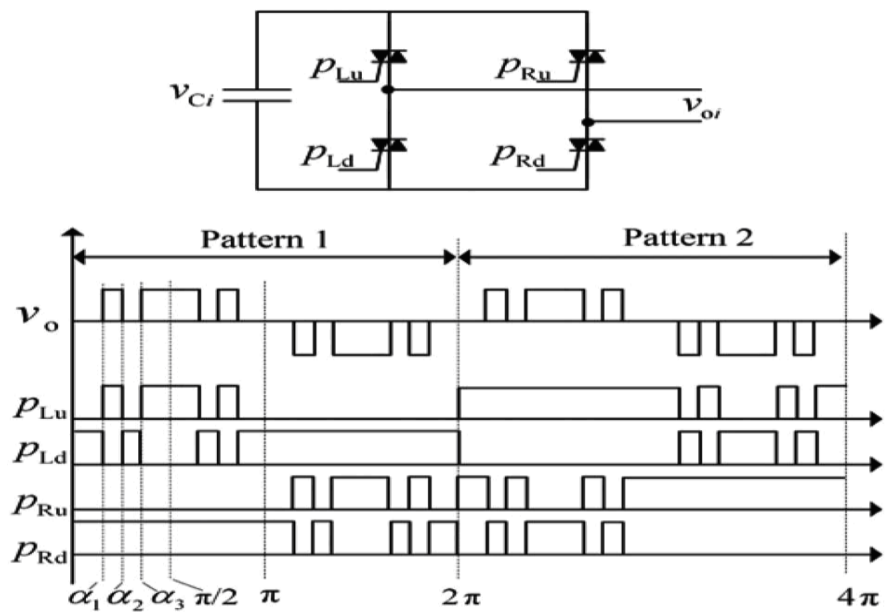

Fig 4: Modulation Technique

They are denoted as Pattern-1 and Pattern-2. Swapping these two gating patterns per cycle can equalize the average conduction time of the switching devices and equalize the devices' current stress. However it should be noted that an additional switching action occurs at the swapping time, which brings unexpected increase of switching loss. To minimize this additional switching loss, the gating-pattern is swapped every ten cycles, instead of one cycle. Thus the increased switching loss brought by gating pattern swapping can be omitted.

\subsection{Calculation of switching angle}

The three switching angles are depicted using $\alpha \mathrm{i} 1-\alpha \mathrm{i} 3$. Since the waveform has quarter wave and half wave symmetry, not even harmonics exist. Normalized with respect to dc voltage, the Fourier coefficient is magnitudes of the output voltage of the $\mathrm{i}^{\text {th }}$ inverter unit is given by,

Where $\mathrm{n}=1,2,3$

$$
h_{i}(n)=(4 / n \pi) \sum_{k=1}^{3}(-1)^{k+1} \cos \left(n \alpha_{i k}\right)
$$


The first optimization objective is to equalize the inverter units' fundamental output voltages.

$$
h_{i}(1)=(4 / \pi) \sum_{k=1}^{3}(-1)^{k+1} \cos \left(\alpha_{i k}\right)=M
$$

Where, $\mathrm{i}=1,2 \ldots \mathrm{N}$

M=Modulation Index

Another optimization objective is the harmonic distortion of the synthesized output voltages. The coefficient magnitude of the nth harmonic of the synthesized phase voltage is given by

$$
h i(n)=(4 / n \pi) \sum_{i=1}^{N} \sum_{k=1}^{3}(-1)^{k+1} \cos \left(n \alpha_{i k}\right)
$$

The minimizing function of the THD is given by

$$
\min F=\sum_{n=3,5,7}^{G} H(n)^{2}
$$

Where, G=2Nk-1

The linear inequality constraint that the minimization should be subjected to is

$$
0<\alpha_{\mathrm{i} 1}<\alpha_{\mathrm{i} 2}<\alpha_{\mathrm{i} 3}<\pi / 2
$$

Using equation (2), (4), (5) switching angles can be calculated using mathematical tool such as MATLAB.

\section{STATCOM}

Fig.5 shows a STATCOM with DC link and a link type GTO converter. Its simplest form includes only one capacitor displaying a single-phase power system and single infinite bus.

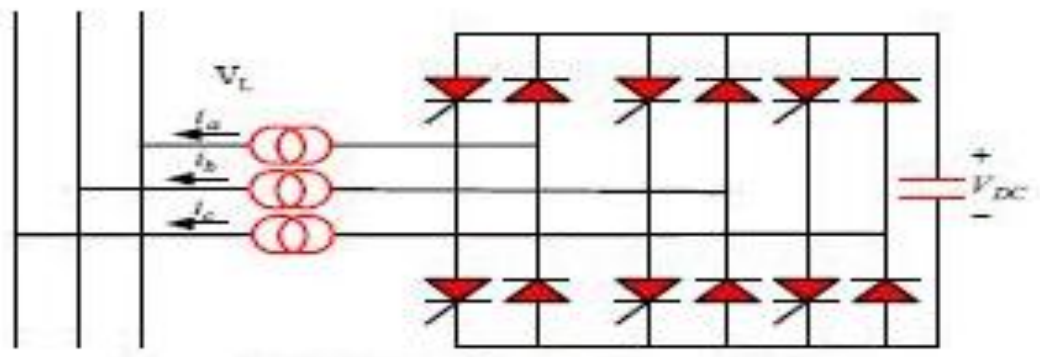

Fig 5: STATCOM with DC link

A major element modeling is that the system can be given it like a current source model, STATCOM performance. It can usually drive for more reactive to consider or before the current phase of the STATCOM are for power system to inject. Because this model at this stage it with the ability that each waveform is STATCOM Sinusoidal current favorite for a very short time and accurately can produce.

It can improve transient stability of FACTS controllers in power are applied. Of these devices to improve transient stability on oscillation equations and methods can be equivalent to levels is explained. The voltage and current equations related to STATCOM is given below.

$$
\begin{aligned}
& \mathrm{V}=-\mathrm{c} \mathrm{I}_{\mathrm{s}} \omega \sin \left(\delta-\delta_{\mathrm{k}}\right) \\
& \mathrm{I}_{\text {STATCOM }}=\mathrm{K}\left(\omega-\omega_{\mathrm{s}}\right) \sin \delta / 2
\end{aligned}
$$


Compensating synchronous static can also plays in the system by increasing and decreasing capacitive power transfer mode and the effect on system stability. Fig.6 shows the effects after the occurrence of an error control method. In this shape changes of potential energy, kinetic energy and energy systems transient error of the whole system after short circuit, despite controlling shows, E is specified in inches STATCOM. Because the first system is in steady state the amount of energy system is zero, then the error system, despite the compensating amount STATCOM system more energy function decreases. These effects of energy function are shown Fig. 7.

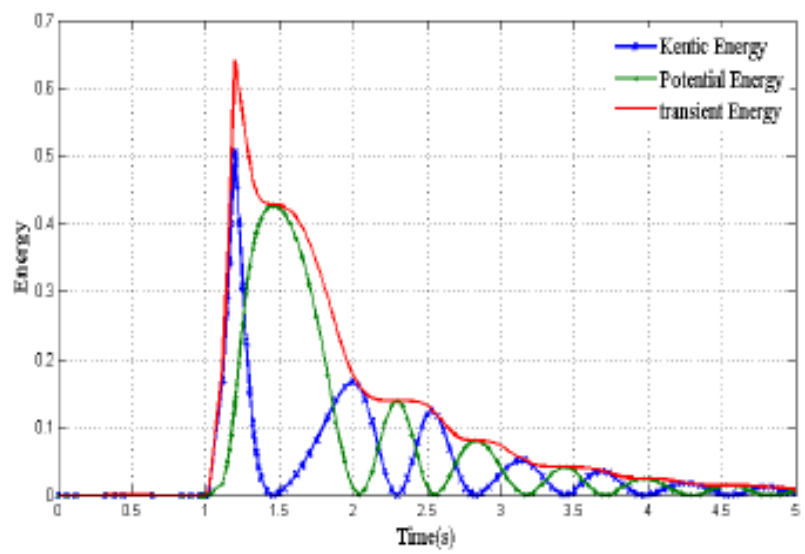

Fig 6: Different Energy levels of STATCOM

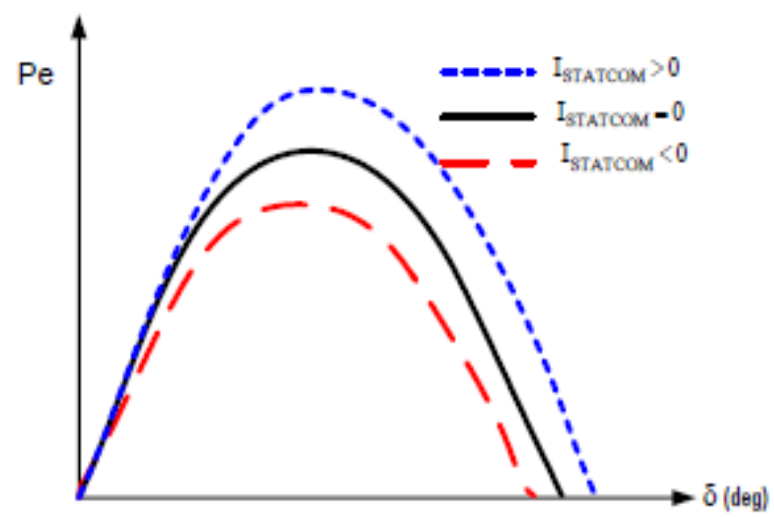

Fig 7: Effects of energy function

\section{NEURO-FUZZY CONTROLLER}

The operating point changes, select an appropriate method of fuzzy inference method. But the rules for determining the fuzzy controller must be followed in an efficient way. The rule of fuzzy inference rules of the system energy function has been used [4-5]. We can obtain rules by a set of combined methods. If the property adaptive and adjustable being added to the fuzzy system, we can obtain Neuro-Fuzzy system. In all of these systems, parameters belonging to the fuzzy rules can be using the property learning neural networks can be set up in each replicate. Work with other concerned about how the formation of laws and functions, membership and range changes, coefficients will not be output. This means every time parameters set and reach their optimum value. Method proposed here using paired input - output system to produce rules and membership functions is used. System ANFIS parameters can be adaptive neural fuzzy inference consumer ANFIS adaptive network and fuzzy controller to regulate terms of educational performance is quite similar inference system, hybrid algorithm to obtain ANFIS is fuzzy [12] uses membership function parameters. In fact, the hybrid method propagation algorithm for training the minimum square error and system as ANFIS uses fuzzy inference.

The network is having five layers. First layer: This layer is related to membership functions; Second layer: This layer is related to the formation of fuzzy rules; Third layer: layer is normalization; Fourth layer: the output of this layer to multiply the output of the third layer in a first order polynomial finds formation; Fifth layer: All 
statements fourth layer has formed. Trained network and the ANFIS method Controller can work with changepoint response is appropriate. This ANFIS controller structure is shown in Fig. 8.

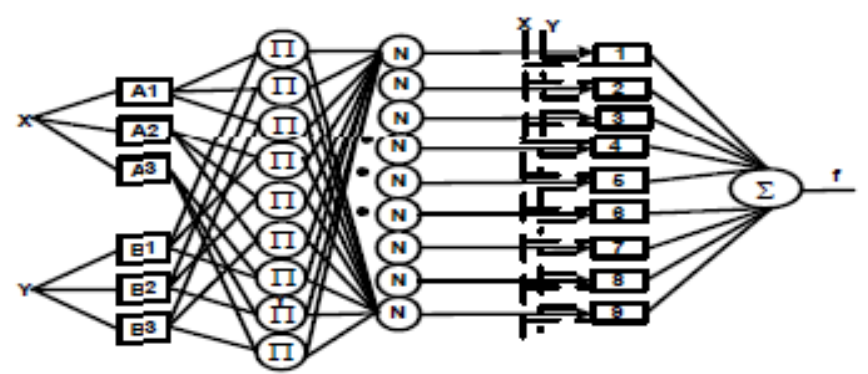

Fig 8: ANFIS Controller Structure

The input signal controlling the angle of internal $\mathrm{R}$ and $\mathrm{Z}$ is rapidly changing output signal flow static synchronous compensation injection fits both input vector is to obtain the neural network training patterns, work is under used. Working with these various conditions can be 50 pairs of input patterns would set a bad exit, the 50 patterns can function criteria Lyapunov well they meet. So that each output function of two vectors is input. Neural network using input signals are a system $\times 2$ and $50 \times$ the output of a matrix, respectively 50 educations so that the result obtained by A. Vrdn laws and interval membership functions and controller is finally better response. After learning process for fuzzy control surface curve - according to neural will be obtained. Level curve for the fuzzy controller trained by ANN is shown in Fig. 9.

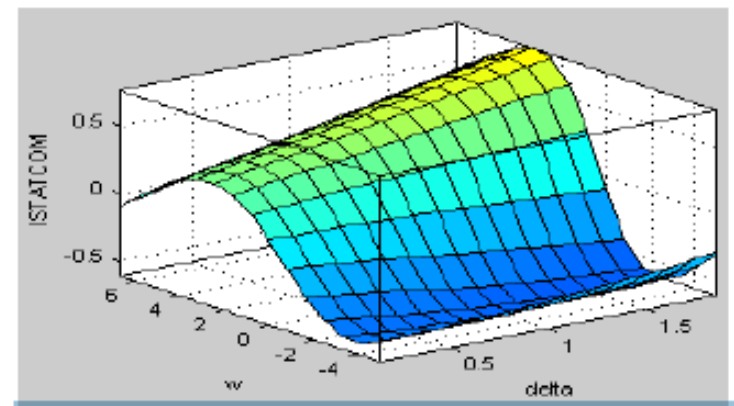

Fig 9: level curve for the fuzzy controller trained by ANN

\section{SIMULATION RESULTS}

The indirect training strategy of ANN for transient stability was evaluated for the range of the modulation index with excellent results in all cases.

Fig. 10 shows the obtained switching angles for various values of modulation index with and without BPA.

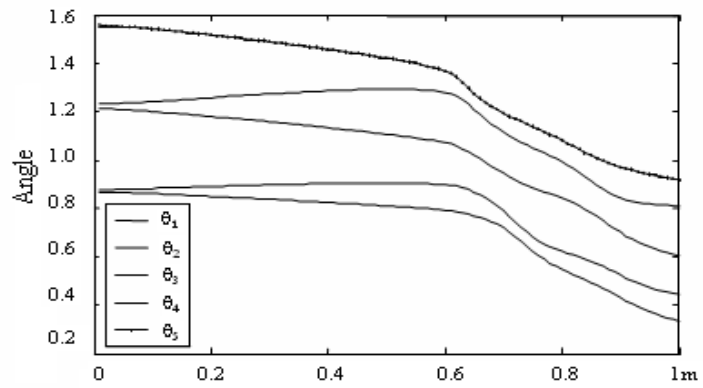

Fig 10: Switching angles after training phase

Fig. 11 shows the output voltage at various load conditions without controller and Fig. 12 shows the real and reactive power of the system at bus 3 without controller. 


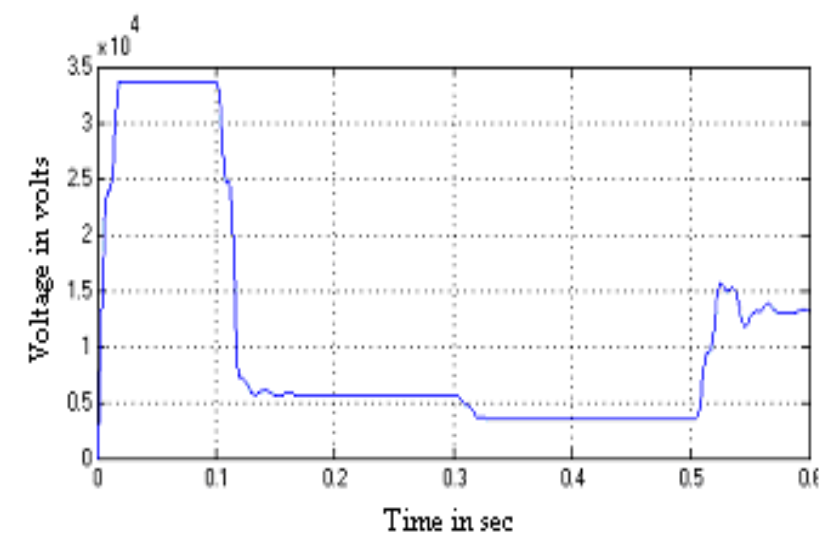

Fig 11: Output Voltage Waveform at Bus 3 without controller

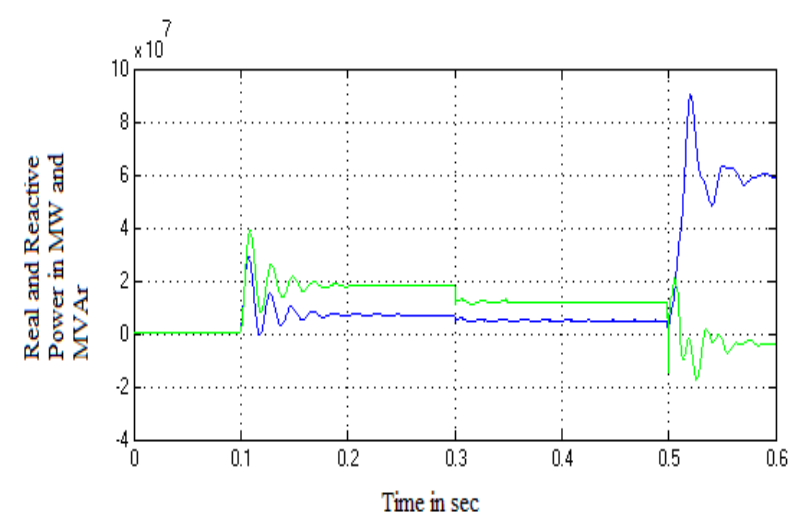

Fig 12: Real and Reactive at Bus 3 without controller

Fig. 13 shows the voltage at bus 3 by using NFC. Fig. 14 shows the real and reactive power of the system at bus 3 by using NFC. From the graph it is inferred that transient period is reduced and also voltage is regulated. Reactive power is reduced and active power is improved. By comparing without compensator, the time critical error is reduced in NC.

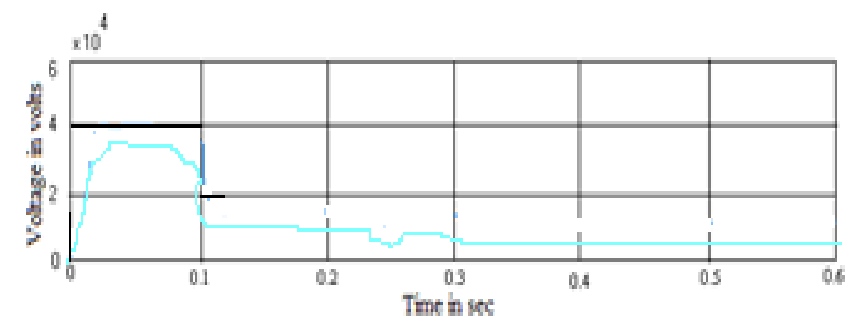

Fig 13: Output Voltage waveform at Bus 3 with NFC

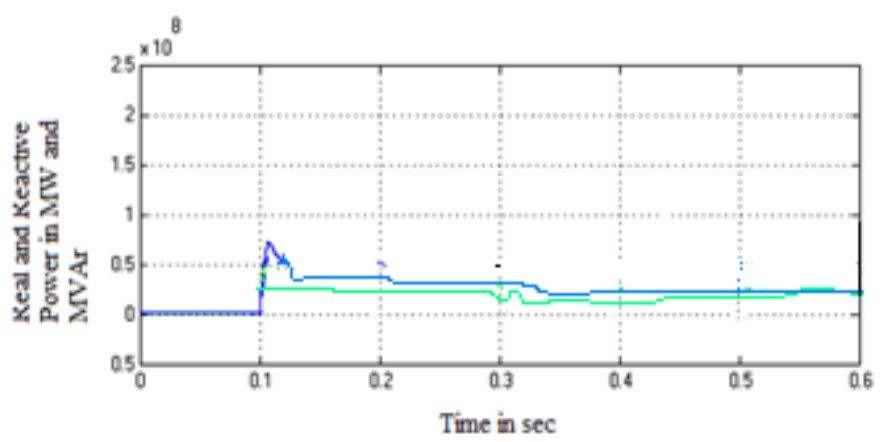

Fig 14: Real and Reactive Power at Bus 3 with NFC

From the graph it is inferred that transient period is reduced and also voltage is regulated. Reactive power is reduced and active power is improved. Compared to without controller case, NFC improves transient 
stability for a network is investigated. Synchronous static in the middle of the line has been a short circuit at the time generator is applied and after bleaching for $200 \mathrm{~ms}$ pure is performing. Table I shows the amount of time to critical error in three cases without controller, FC, NC and NFC. Comparing the three time drive controller, transient stability improvement is evident in NFC.

Table 1: Comparison of time critical error

\begin{tabular}{|c|c|c|}
\hline Controller & Without Controller & NFC \\
\hline Time Critical in sec & $1 / 185$ & $1 / 219$ \\
\hline
\end{tabular}

\section{CONCLUSION}

A NFC controller is designed based on energy function lyapunov, for compensating the effect of synchronous after the system disturbance. For switching the device, swapping technique is adopted. The scheme of gating-pattern swapping among the various devices can equalize device current stresses. A multilevel optimal modulation strategy was proposed for STATCOM, is incorporated in system line. So the system is easily balanced. NFC is employed to enhance the transient stability. It is inferred from the graph transient is reduced using NFC. Finally the proposed system reduces the critical time error.

\section{APPENDIX \\ For STATCOM}

Rated Power $=100$ MVAr

Rated voltage $=138 \mathrm{kV}$

Interface inductor $(\mathrm{L})=2.86 \mathrm{mH}$

Resistance $(\mathrm{Rs})=0.0898 \Omega$

For grid

Rated Voltage: $230 \mathrm{kV}$

Short Circuit Capacity: 10000 MVA

For Power Transformer (Y/Y)

Rated Voltage 220 kV/33 kV

Rated Power: 300 MVA

For Coupling Transformer (Y/Y)

Rated Voltage $138 \mathrm{kV} / 230 \mathrm{kV}$

Rated Power: 100 MVA

Three Phase Load

Load 1:

$\mathrm{P}=100 \mathrm{MW}$

$\mathrm{Q}=80 \mathrm{MVAr}$

Load 2:

$\mathrm{P}=70 \mathrm{MW}$

$\mathrm{Q}=50 \mathrm{MVAr}$

Load 3:

$\mathrm{P}=60 \mathrm{MW}$

$\mathrm{Q}=40 \mathrm{MVAr}$

\section{REFERENCES}

[1] B. Boussahoua M. Boudou, Power System Transient Stability Robust Control Using Fuzzy Logic PSS and Genetic Algrithm, Journal of Electrical Engineering, Vol. 11, Edition 2, 2011, pp.79-83.

[2] J. S. Lai and F. Z. Peng, Multilevel converters-A new breed of power converters, IEEE Trans. Ind. Appl., Vol. 32, no. 3, May/Jun. 1996, pp. 509-517.

[3] F. Z. Peng, J. -S. Lai, J. W. McKeever, and J. VanCoevering, A multilevel VSI with separate DC sources for static VAR generation, IEEE Trans. Ind. Appl., Vol. 32, no. 5, Sep./Oct. 1996, pp. 1130-1138.

[4] P. M. Bhagwat and V. R. Stefanovic, Generalized structure of a multilevel PWM inverter, IEEE Trans. Ind. App., Vol. 19, Nov./Dec. 1983, pp. 1057-1069.

[5] M. Marchesoni and M. Mazzucchelli, Multilevel converter for high power ac drives: A review, IEEE Symp. Indl. Electrs., 1993, pp.38-43.

[6] H. Akagi, The state-of-the-art of power electronics in Japan, IEEE Trans. Power Electron. Vol. 13, Mar. 1998, pp. 345-356.

[7] G. Carrara, S. Gardella, M. Marchesoni, R. Salutari, and G. Sciutto, A new multilevel PWM method: A theoretical analysis, IEEE Trans. Power Electron., Vol. 7, July 1992, pp. 497-505.

[8] B. Mwinyiwiwa, Z. Wolanski, and B. T. Ooi, Microprocessor-implemented SPWM for multi converters with phase-shifted triangle carriers, IEEE Trans. Ind. Appl. Vol. 34, May/June 1998, pp. 487-494.

[9] S. Ogasawara, J. Takagaki, H. Akagi, and A. Nabae, A novel control scheme of a parallel current-controlled PWM inverter, IEEE Trans. Ind. Applicat., Vol. 28, Sept. / Oct. 1992, pp. 1023-1030. 
[10] F. Ueda, K. Matsui, M. Asao, and K. Tsuboi, Parallel-connections of PWM inverters using current sharing reactors, IEEE Trans. Power Electron. Vol. 10, Nov. 1995, pp. 673-679.

[11] D.Daniolos, M.K.Darwish and P.Mehta, "Optimised PWM inverter control using Artificial Neural Networks", IEE 1995 Electronics Letters Online, No. 19951186, 14 August 1995, pp. 1739-1740.

[12] A.M.Trzynadlowski and S.Legowski, "Application of Neural Networks to the Optimal Control of Three-Phase Voltage-Controlled Inverters", IEEE Transactions on Power Electronics, Vol.9, No.4, July 1994, pp.397-402.

[13] M.Mohaddes, A.M.Gole and P.G.McLaren, "A Neural Network controlled Optimal pulse-width modulated STATCOM", IEEE Transactions on Power Delivery, Vol. 14, Issue:2, April 1999, pp.481-488.

[14] S. Mori, et al., Development of a Large Static Var Generator Using Self-Commutated Inverters for Improving Power Systems Stability, IEEE Trans. Power Delivery, Vol. 8, No.1, Feb.1993, pp. 371-377.

[15] N. Seki, H. Uchino, Converter Configurations and Switching Frequency for GTO Reactive Power Compensator, IEEE Trans. on Industry Applications, Vol. 33, No. 4, July/August 1997.

[16] S.A. Al-Mawsawi, Fuzzy Control and Dynamic Performance of $\quad$ STATCOM, IETECH J. of Elec. Analysis, 2007, Vol.1, No. 2, pp. 104-115.

[17] A. Ajami, S.H. Hosseini, Application of a Fuzzy Controller for Transient Stability Enhancement of AC Transmission System by STATCOM, Intl. Joint Conf. ICASE, October 2002, pp. 6059 - 6063.

[18] Yasser Ashkhane Mahdi Zarif, Voltage Stability Improvement by STATCOM in a Weak Network with Wind Generation, Journal of Electrical Engineering, Vol. 11, Edition 1, 2011, pp. 57-64. 